NASA/TM-2002-211374

\title{
Probabilistic Study of Fluid Structure Interaction
}

Rama S.R. Gorla

Cleveland State University, Cleveland, Ohio

Shantaram S. Pai and Jeffrey J. Rusick

Glenn Research Center, Cleveland, Ohio 
Since its founding, NASA has been dedicated to the advancement of aeronautics and space science. The NASA Scientific and Technical Information (STI) Program Office plays a key part in helping NASA maintain this important role.

The NASA STI Program Office is operated by Langley Research Center, the Lead Center for NASA's scientific and technical information. The NASA STI Program Office provides access to the NASA STI Database, the largest collection of aeronautical and space science STI in the world. The Program Office is also NASA's institutional mechanism for disseminating the results of its research and development activities. These results are published by NASA in the NASA STI Report Series, which includes the following report types:

- $\quad$ TECHNICAL PUBLICATION. Reports of completed research or a major significant phase of research that present the results of NASA programs and include extensive data or theoretical analysis. Includes compilations of significant scientific and technical data and information deemed to be of continuing reference value. NASA's counterpart of peerreviewed formal professional papers but has less stringent limitations on manuscript length and extent of graphic presentations.

- TECHNICAL MEMORANDUM. Scientific and technical findings that are preliminary or of specialized interest, e.g., quick release reports, working papers, and bibliographies that contain minimal annotation. Does not contain extensive analysis.

- CONTRACTOR REPORT. Scientific and technical findings by NASA-sponsored contractors and grantees.
- CONFERENCE PUBLICATION. Collected papers from scientific and technical conferences, symposia, seminars, or other meetings sponsored or cosponsored by NASA.

- SPECIAL PUBLICATION. Scientific, technical, or historical information from NASA programs, projects, and missions, often concerned with subjects having substantial public interest.

- TECHNICAL TRANSLATION. Englishlanguage translations of foreign scientific and technical material pertinent to NASA's mission.

Specialized services that complement the STI Program Office's diverse offerings include creating custom thesauri, building customized data bases, organizing and publishing research results ... even providing videos.

For more information about the NASA STI Program Office, see the following:

- Access the NASA STI Program Home Page at http://www.sti.nasa.gov

- E-mail your question via the Internet to help@sti.nasa.gov

- Fax your question to the NASA Access Help Desk at 301-621-0134

- Telephone the NASA Access Help Desk at 301-621-0390

- Write to:

NASA Access Help Desk

NASA Center for AeroSpace Information 7121 Standard Drive

Hanover, MD 21076 
NASA/TM-2002-211374

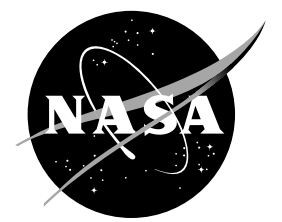

\section{Probabilistic Study of Fluid Structure Interaction}

Rama S.R. Gorla

Cleveland State University, Cleveland, Ohio

Shantaram S. Pai and Jeffrey J. Rusick

Glenn Research Center, Cleveland, Ohio

Prepared for the

Turbo Expo 2002

sponsored by the American Society of Mechanical Engineers and the International Gas Turbine Institute

Amsterdam, The Netherlands, June 3-6, 2002

National Aeronautics and

Space Administration

Glenn Research Center 


\section{Acknowledgments}

The authors are grateful to Dr. Christos Chamis of NASA Glenn Research Center for his technical guidance. The technical assistance given by N\&R Engineering \& Management Services is acknowledged.

Available from

NASA Center for Aerospace Information 7121 Standard Drive

Hanover, MD 21076
National Technical Information Service 5285 Port Royal Road Springfield, VA 22100

Available electronically at http://gltrs.grc.nasa.gov/GLTRS 


\title{
PROBABILISTIC STUDY OF FLUID STRUCTURE INTERACTION
}

\author{
Rama S.R. Gorla \\ Cleveland State University \\ Cleveland, Ohio 44115 \\ Shantaram S. Pai and Jeffrey J. Rusick \\ National Aeronautics and Space Administration \\ Glenn Research Center \\ Cleveland, Ohio 44135
}

\begin{abstract}
A combustor liner was computationally simulated and probabilistically evaluated in view of the several uncertainties in the aerodynamic, structural, material and thermal variables that govern the combustor liner. The interconnection between the computational fluid dynamics code and the finite element structural analysis codes was necessary to couple the thermal profiles with structural design. The stresses and their variations were evaluated at critical points on the liner. Cumulative distribution functions and sensitivity factors were computed for stress responses due to the aerodynamic, mechanical and thermal random variables. It was observed that the inlet and exit temperatures have a lot of influence on the hoop stress. For prescribed values of inlet and exit temperatures, the Reynolds number of the flow, coefficient of thermal expansion, gas emissivity and absorptivity and thermal conductivity of the material have about the same impact on the hoop stress. These results can be used to quickly identify the most critical design variables in order to optimize the design and make it cost effective.
\end{abstract}

\section{INTRODUCTION}

Predictive technologies based on a probabilistic method of problem solving are gaining a steady foothold as a method of finding answers to engineering problems. These can be used for design, sensitivity analysis, mathematical modeling of complex processes, uncertainty analysis, competitive analysis and process optimization. With the increase in gas turbine engine structural complexity and performance over the past 50 years, structural engineers have created an array of safety nets to ensure against component failures in turbine engines. In order to reduce what is now considered to be excessive conservatism and yet maintain the same adequate margins of safety, there is a pressing need to explore methods of incorporating probabilistic design procedures into engine development. Probabilistic methods combine and prioritize the statistical distributions of each design variable, generate an interactive distribution and offer the designer a quantified relationship between robustness, endurance and performance. The designer can therefore iterate between weight reduction, life increase, engine size reduction, speed increase, etc.

Fox [1] developed a design system that integrated the deterministic design methods with probabilistic design techniques. Here, two different approaches were used for estimating uncertainty. A Monte Carlo approach was used on design codes that were judged to run relatively quickly. For more computationally intensive design codes, a second order response surface model in conjunction with Box-Behnken design experiments was used and then a Monte Carlo simulation was executed. Lykins and Thompson [2] and Thompson and Fecke [3] developed a system for probabilistic design of gas turbine engines. They relied on direct numerical integration using closed form solutions by fast probability integration to establish risk estimates.

Several researchers at NASA Glenn Research Center have applied the probabilistic design approaches to turbine engines and related systems. Chamis [4] developed a Probabilistic Structural Analysis Method (PSAM) using different distributions such as the Weibull, normal, log-normal etc. to describe the uncertainties in the structural and load parameters or primitive variables. Nagpal, Rubinstein, and Chamis [5] presented a probabilistic study of turbopump blades of the Space Shuttle Main Engine (SSME). They found that random variations or uncertainties in geometry have statistically significant influence on the response variable and random variations in material properties have statistically insignificant effects. Chamis [6] summarized the usefulness and importance of the probabilistic approach, especially for turbopumps. Pai and Chamis [7] outlined the probabilistic evaluation of the buckling of truss structures for non-uniform thermal loads, other loads and moments using the NESSUS computer code. Their results indicated that the buckling loads and member axial forces are most sensitive to the uncertainties in geometry variables. The structural and thermal aspects of the probabilistic assessment of a combustor liner design were reported by Pai and Chamis [8]. 
Probabilistic CFD design is needed because the flow effects on structures will have to be described more accurately. To cost effectively accomplish the design task, we need to formally quantify the effect of uncertainties (variables) in the design. Probabilistic design is one effective method to formally quantify the effect of uncertainties. It is essential to strengthen the structural probabilistic analysis capability to include aerodynamic and heat transfer uncertainties. The objective is to establish a revolutionary new early design process, by developing non-deterministic physics-based probabilistic design tools, which will include all the life cycle processes. Breakthroughs will be sought in speed, accuracy, intelligence, and usability of the system.

A new three-dimensional approach was developed to investigate the application of a parametric optimization method coupled with a CFD Navier-Stokes analysis code, NPARC [9] for the aerothermal design of a combustor liner. The general benefits of the proposed computational research will be improvements to both accuracy and efficiency of the present analysis techniques and will provide savings in computational simulation efforts as well as greater understanding of flow physics issues associated with turbomachinery design.

\section{GOVERNING EQUATIONS AND COMPUTATIONAL FLUID DYNAMICS METHOD}

The governing equations are the three-dimensional, unsteady, compressible Navier-Stokes equations coupled with the k- $\omega$ SST turbulence model and may be written as:

$$
\begin{aligned}
& \frac{\partial \rho}{\partial t}+\frac{\partial}{\partial x_{j}}\left(\rho u_{j}\right)=0 \\
& \frac{\partial}{\partial t}\left(\rho u_{i}\right)+\frac{\partial}{\partial x_{j}}\left(\rho u_{j} u_{i}\right)=-\frac{\partial p}{\partial x_{i}}+\frac{\partial \hat{\tau}_{i j}}{\partial x_{j}} \\
& \frac{\partial \rho E}{\partial t}+\frac{\partial}{\partial x_{j}}\left(\rho E u_{j}\right)=-\frac{\partial p u_{j}}{\partial x_{j}}+\frac{\partial}{\partial x_{j}}\left[u_{i} \hat{\tau}_{i j}-q_{j}\right] \\
& \frac{\partial \rho k}{\partial t}+\frac{\partial}{\partial x_{j}}\left(\rho k u_{j}\right)=\tau_{i j} \frac{\partial u_{i}}{\partial x_{j}}-\beta^{*} \rho \omega k+\frac{\partial}{\partial x_{j}}\left[\left(\mu+\sigma_{k} \mu_{T}\right) \frac{\partial k}{\partial x_{j}}\right] \\
& \frac{\partial \rho \omega}{\partial t}+\frac{\partial}{\partial x_{j}}\left(\rho \omega u_{j}\right)=\frac{\gamma}{v_{T}} \tau_{i j} \frac{\partial u_{i}}{\partial x_{j}}-\beta \rho \omega^{2} \\
& \quad+\frac{\partial}{\partial x_{j}}\left[\left(\mu+\sigma_{\omega} \mu_{T}\right) \frac{\partial \omega}{\partial x_{j}}\right]+2\left(1-F_{1}\right) \rho \sigma_{\omega 2} \frac{1}{\omega} \frac{\partial k}{\partial x_{j}} \frac{\partial \omega}{\partial x_{j}}
\end{aligned}
$$

where $E$ represents the total energy and $\tau_{i j}$ are composed of molecular and Reynolds stresses, defined as

$$
\begin{gathered}
\hat{\tau}_{i j}=2 \mu\left(S_{i j}-\frac{S_{k k} \delta_{i j}}{3}\right)+\tau_{i j} \\
\tau_{i j}=2 \mu_{T}\left(S_{i j}-\frac{S_{k k} \delta_{i j}}{3}\right)-\frac{2 \rho k \delta_{i j}}{3}, S_{i j}=\frac{1}{2}\left(\frac{\partial u_{i}}{\partial x_{j}}+\frac{\partial u_{j}}{\partial x_{i}}\right)
\end{gathered}
$$

and where $\mathrm{q}_{\mathrm{j}}$ is the total heat-flux rate defined as

$$
q_{j}=-\left(\frac{\gamma}{\gamma-1}\right)\left(\frac{\mu}{\operatorname{Pr}}+\frac{\mu_{T}}{\operatorname{Pr}_{T}}\right) \frac{\partial T}{\partial x_{j}}
$$

The turbulent eddy viscosity is defined as

$$
\mu_{T}=0.31 \rho k / \max \left(0.31 \omega ; \Omega F_{2}\right)
$$

where $F_{1}$ and $F_{2}$ are turbulence functions and $\Omega$ is the absolute value of vorticity. The idea is to retain the robust and accurate formulation of the Wilcox [11] $\mathrm{k}-\omega$ model in the near wall region and to take advantage of the free stream independence of the k- $\varepsilon$ model in the outer part of the boundary layer. To achieve this, the $\mathrm{k}-\varepsilon$ model is transformed into a $\mathrm{k}-\omega$ formulation. The original model is then multiplied by a function $F_{1}$ and the transformed model by a function $\left(1-F_{1}\right)$ and both are added together. The function $F_{1}$ will be designed to be one in the near wall region and zero away from the surface. The blending will take place in the wake region of the boundary layer. Similarly, $F_{2}$ is used as a blending function for the eddy viscosity model. More details about the turbulence models can be found in Ref. [10]. The equation of state is introduced to complete the set of the governing equations as

$$
p=\rho(\gamma-1)\left[E-\frac{1}{2} u_{i} u_{i}-k\right]
$$

The governing equations are transformed in generalized coordinates and are solved with a finite volume method. With a backward Euler implicit method, the governing equations are discretized in time and linearized in delta form as

$$
\left(\frac{I}{J \Delta t}+\left[\frac{\partial R}{\partial Q}\right]^{n}\right) \Delta Q=-R^{n}
$$

where $J$ is the Jacobian of transformation, $R$ is the residual of the steady-state flow equations, and $Q$ is the six-element vector of conservative variables $(\rho, \rho u, \rho v, \rho e, \rho k, \rho w)^{T}$.

For the calculation of the residual, convective terms are upwind differenced based on Roe's flux difference splitting (FDS) scheme [12], and viscous terms are central differenced. The third order of spatial accuracy is kept in all calculations.

The flow simulations were performed by obtaining a converged steady state flow solution. The steady state simulation to initialize the flow field was done with the approximate factorization algorithm using local time stepping. Typically, about 2500 time steps were required to reduce the $\mathrm{L}_{2}$ norm to about $10^{-7}$. For the time accurate computations, a five step Jameson algorithm second order accurate in time was selected. The time step throughout the grid block was set to a constant equal to the Courant-Friedrichs-Lewy (CFL) limit specified by the global time step (DTCAP) at the location of maximum change in the flow variables. This option provides the most rapid time-accurate simulation. 


\section{GRID GEOMETRY DESCRIPTION}

Figure 1 shows a single grid block used for computations. The flow incidence angle was specified and the backpressure is adjusted until the average Mach number along the inflow boundary matches a specified value. Computational grids were generated using the GRIDGEN3D [13] grid generation program. Uniform grid spacing was used in each coordinate direction. A grid refinement study was completed to ensure that the computed results were independent of the grid density. The combustor liner was axisymmetric. A grid of 97 x 101 was selected for the combustor liner aerodynamic simulations.

\section{THE PROBABILISTIC STRUCTURAL ANALYSIS CODE, NESTEM}

NESTEM [14] is an enhanced version of NESSUS (Numerical Evaluation of Stochastic Structures Under Stress) developed by NASA Glenn Research Center. NESTEM maintains all the capabilities of NESSUS, including structural analysis using a finite element approach and adds three significant features, namely, heat transfer analysis, geometry generation and ceramic material property generation. The code combines state of the art probabilistic algorithms with generalpurpose structural analysis methods to compute the probabilistic response and the reliability of engineering structures. Uncertainty in loading, material properties, geometry, boundary conditions and initial conditions can be simulated. The structural analysis methods include nonlinear finite element methods and boundary element methods. Several probabilistic algorithms are available such as the advanced mean value method and the adaptive importance sampling method. The application of the code includes probabilistic structural response, component and system reliability and risk analysis of structures considering cost of failure. The basic heat transfer variables can be included as random variables along with the mechanical random variables to quantify risk using probabilistic methods to perform sensitivity analysis.

In general, the finite element equations of motion may be written as:

$$
[\mathrm{M}]\{\ddot{u}\}+[\mathrm{C}]\{\dot{u}\}+[\mathrm{K}]\{\mathrm{u}\}=\mathrm{F}(\mathrm{t})
$$

Here, $[\mathrm{M}],[\mathrm{C}]$ and $[\mathrm{K}]$ denote the mass, damping and stiffness matrices respectively. Further more, $\{\ddot{u}\},\{\dot{u}\}$ and $\{\mathrm{u}\}$ are the acceleration, velocity and displacement vectors at each node, respectively. The forcing function $\mathrm{F}(\mathrm{t})$ is time independent at each node.

In this paper, the static case is considered by setting the mass and damping matrices to zero and considering the forcing function to be independent of time in Eq. (7) such that

$$
[\mathrm{K}]\{\mathrm{u}\}=\mathrm{F}
$$

\section{COMPUTATIONAL APPROACH BY THE COUPLING OF CFD AND NESTEM CODES}

A thorough literature search has revealed that so far, no one has reported in the literature on the probabilistic study based upon the coupling of the computational fluid dynamics and structural finite element analysis. Therefore, the present study was undertaken in order to accomplish this task. The NPARC [9] program performs aerodynamic analyses for all mean and perturbed values of the random aerodynamic variables. The environmental temperature distribution along the length of the combustor liner was computed in each case. A typical plot of the environmental temperature is provided in Figure 2. The NESTEM program performs heat transfer analyses for all mean and perturbed heat transfer and mechanical random variables using the environmental temperature data. Once all the response analyses are completed, the program uses that data for a probabilistic analysis using the fast probability integration (FPI) module. This module determines the probabilistic distribution and sensitivity factors for the respective random variables.

The proposed methodology will be demonstrated by applying it to a combustor liner assuming uncertainties in the random variables. The liner is made of Haynes alloy, 9.5 inches long, 50 inches inner diameter and 0.1 inch thick. A finite element model was created using 1400 eight node brick elements and 2400 nodes. There were two elements through the thickness and 100 elements around the circumference. All nodes on the left end of the liner were held against axial translation. On this end, nodes on the inside surface and located at ninety degrees from each other were held tangentially. Thus, the liner was free to expand in both radial and axial directions.

The aerodynamic, mechanical and thermal random variables and their respective values used in this analysis are shown in Table 1. All the random variables were assumed to be independent. A scatter of $\pm 20 \%$ was specified for all the variables. This variation amounted to two standard deviations. Although the variations chosen may not be realistic, they can be used to illustrate the procedure used and validate the approach. Normal distribution was assumed for all random variable scatters. Figure 3 shows the various steps in the probabilistic CFD and structural analysis.

\section{DISCUSSION OF RESULTS}

Maximum hoop stress location was determined from a preanalysis of the combustor liner. This location was used to evaluate the cumulative distribution functions (CDF) and the sensitivity factors for stress response. CDF for the hoop stress is shown in Figure 4. The sensitivity factors for hoop stress versus the random variables are plotted in Figures 5 to 9 . Table 2 shows the details of the random variables. From Figures 5 to 9 we observe that the inlet and exit temperatures have a lot of influence on the hoop stress. For prescribed values of inlet and exit temperatures, the Reynolds number of the flow, coefficient of thermal expansion, gas emissivity and absorptivity and thermal conductivity of the material have a lot of impact on the hoop stress. These results can be used to further optimize the design for cost effectiveness.

\section{CONCLUDING REMARKS}

In this paper, a non-deterministic, non-traditional method has been developed to support reliability-based aerospace design. The revolutionary part of the proposed work is the probabilistic evaluation of the Computational Fluid Dynamics (CFD) methodology. The nontraditional part of the proposed 
work is the identification of criteria for using different materials and computational accuracy. Probabilistic methods were applied to the aerothermodynamics of a combustor liner by developing novel concepts for lowering the computational cost. The interconnection between the CFD code and NESTEM codes was necessary to couple the thermal profiles with structural design. Stresses and their variations were evaluated at critical points on the liner using the random variables including the aerodynamic variables, material properties, pressure loading and basic heat transfer variables. Cumulative distribution functions and sensitivity factors were computed for stress responses due to the aerodynamic, mechanical and thermal random variables. Results show that the hoop stress will be less than $50 \mathrm{MPa}$ (7500 Psi) with about $1 \%$ probability and will be greater than $200 \mathrm{MPa}(30,000 \mathrm{Psi})$ with a probability of $99 \%$. The deterministic value of hoop stress is given by $113 \mathrm{MPa}(17,000 \mathrm{Psi})$. The inlet and exit temperatures primarily affect the results. Evaluating probability of risk and sensitivity factors will enable the identification of the most critical design variables in order to optimize the design and make it cost effective.

\section{ACKNOWLEDGMENTS}

The authors are grateful to Dr. Christos Chamis of NASA Glenn Research Center for his technical guidance. The technical assistance given by N\&R Engineering \& Management Services is acknowledged.

\section{REFERENCES}

1. Fox, E.P., 1994, "The Pratt \& Whitney Probabilistic Design System," AIAA-94-1442-CP.

2. Lykins, C., Thompson, D., and Pomfret, C., 1994, "The Air Force's Application of Probabilistics to Gas Turbine Engines," AIAA-94-440-CP.

3. Thompson, D. and Fecke, G., 1992, "Air Force Perspective on Probabilistic Design," Reliability Technology, Vol. 28, pp. 1-7.

4. Chamis, C.C., 1986, "Probabilistic Structural Analysis Methods for Space Components," Space Systems Technology Conference, San Diego, California.
5. Nagpal, V.K., Rubinstein, R., and Chamis, C.C., 1987, "Probabilistic Structural Analysis to Quantify Uncertainties Associated with Turbopump Blades," AIAA 87-0766.

6. Chamis, C.C., 1986, "Probabilistic Structural Analysis Methods for Critical SSME Propulsion Components," Third Space Systems Technology Conference, AIAA, pp. 133-144.

7. Pai, S.S. and Chamis, C.C., 1992, "Probabilistic Assessment of Space Trusses Subjected to Combined Mechanical and Thermal Loads," NASA TM-105429.

8. Pai, S.S. and Chamis, C.C., 1995, "Probabilistic Assessment of Combustor Liner Design," ASME Paper 95-GT-121.

9. Rigby, D.L., 1996, "Compact Spatial Differencing and Subiteration Time Marching in the NPARC Code," AIAA Paper 96-0385.

10. Menter, F.R., 1994, "Two-Equation Eddy-Viscosity Turbulence Models for Engineering Applications," AIAA Journal, Vol. 32, pp. 1598-1605.

11. Wilcox, D.C., 1993, "Comparison of Two-Equation Turbulence Models for Boundary Layers with Pressure Gradient," AIAA Journal, Vol. 31, No. 8, pp. 1414-1421.

12. Roe, P.L., 1981, "Approximate Riemann Solvers, Parameter Vectors and Difference Schemes," Journal of Computational Physics, Vol. 43, pp. 357-372.

13. Steinbrenner, J.P., Chawner, J.R. and Fouts, C.L., 1990, "The GRIDGEN3D Multiple Block Grid Generation System," General Dynamics Corp., WRDC-TR-90-3022, Vols. 1 and 2, Fort Worth, Texas.

14. Patel, B., Strack, W., Nagpal, V., Pai, S.S., and Murthy P.L.N., 1999, "NESTEM: Probabilistic Heat Transfer/Structural Analysis Tool," 23rd Annual Conference on Composites, Materials, and Structures, Cocoa Beach, Florida. 
Table 1.-Random variables

\begin{tabular}{|l|c|}
\hline \multicolumn{1}{|c|}{ Random Variable } & Mean Value \\
\hline Mach number & 0.3 \\
\hline Reynolds number & $1.6591036 \mathrm{E} 07$ \\
\hline Turbulence intensity & 0.05 \\
\hline Inlet Total Pressure & $150 \mathrm{Psi}$ \\
\hline Inlet Total Temperature & $3460 \mathrm{R}$ \\
\hline Exit Temperature & $3460 \mathrm{R}$ \\
\hline Angle of attack & $5 \mathrm{degrees}$ \\
\hline Coefficient of thermal expansion & $9.5 \mathrm{E}-06 \mathrm{per}{ }^{\circ} \mathrm{F}$ \\
\hline Modulus of Elasticity & $23 \mathrm{E}+06 \mathrm{Psi}$ \\
\hline Poisson's ratio & 0.3 \\
\hline Emissivity of surface & 0.8 \\
\hline Gas Emissivity inside & 0.71 \\
\hline Gas absorptivity inside & 0.52 \\
\hline Conductivity axial & $16.67 \mathrm{BTU} / \mathrm{hr} \mathrm{ft}^{\circ} \mathrm{F}$ \\
\hline Conductivity tangential & $16.67 \mathrm{BTU} / \mathrm{hr} \mathrm{ft}{ }^{\circ} \mathrm{F}$ \\
\hline Conductivity through thickness & $\mathrm{BTU} / \mathrm{hr} \mathrm{ft}{ }^{\circ} \mathrm{F}$ \\
\hline
\end{tabular}

Table 2.- Random variable labels

\begin{tabular}{|l|l|}
\hline \multicolumn{1}{|c|}{ Label } & \multicolumn{1}{c|}{ Description } \\
\hline ANGLE & Angle of attack for flow \\
\hline CKXX & Thermal conductivity in axial direction \\
\hline CKYY & Thermal conductivity in tangential direction \\
\hline CKZZ & Thermal conductivity in thickness direction \\
\hline COEFF & Coefficient of thermal expansion \\
\hline EMIS12 & Surface emissivity \\
\hline GABS12 & Gas absorptivity \\
\hline GEMIS12 & Gas emissivity \\
\hline MACHNO & Mach number \\
\hline MODULUS & Modulus of elasticity \\
\hline POISSON & Poisson's ratio \\
\hline PRESSIN & Inlet pressure \\
\hline REYNOLD & Reynolds number \\
\hline TEMPEX & Exit temperature \\
\hline TEMPIN & Inlet temperature \\
\hline TURBINT & Turbulent intensity \\
\hline
\end{tabular}




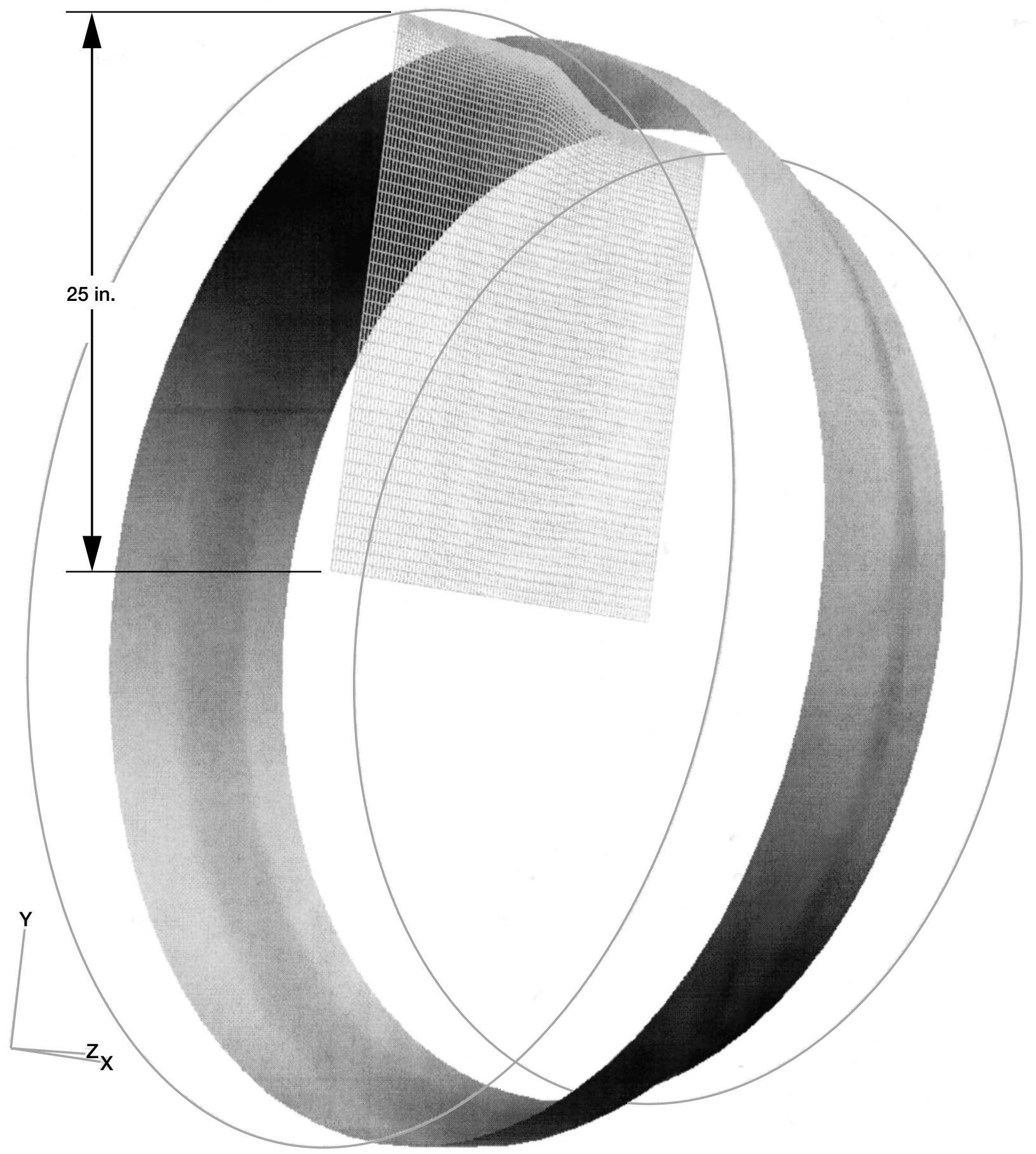

Figure 1.-Grid for combustor liner. 


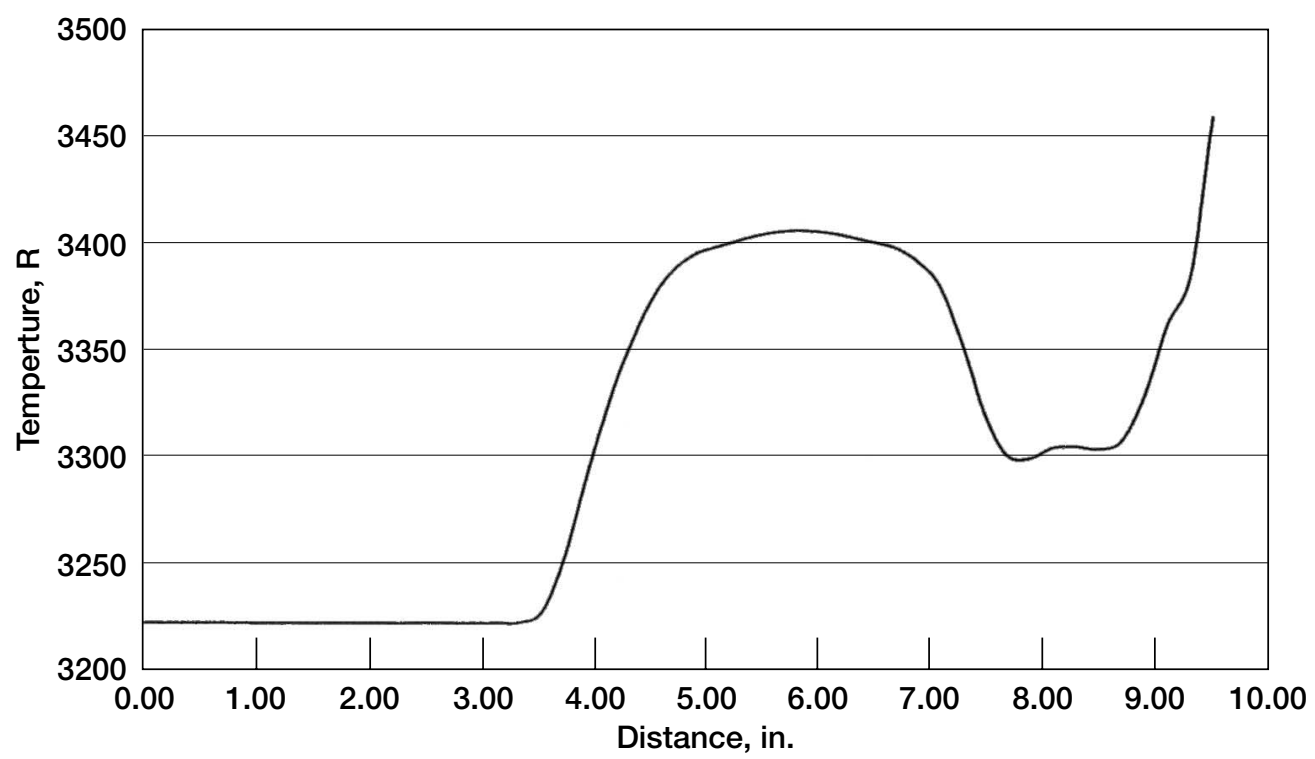

Figure 2.-Combustor liner environmental temperature.

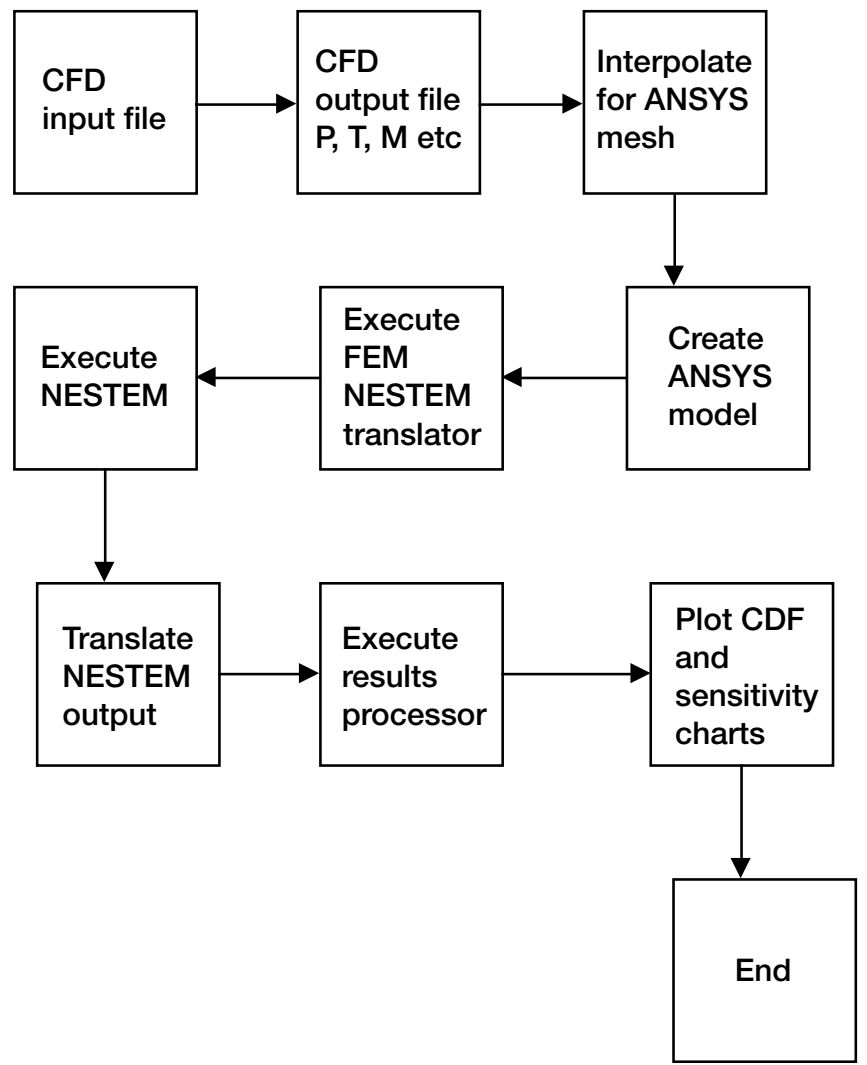

Figure 3.-Probabilistic CFD and structural analysis. 


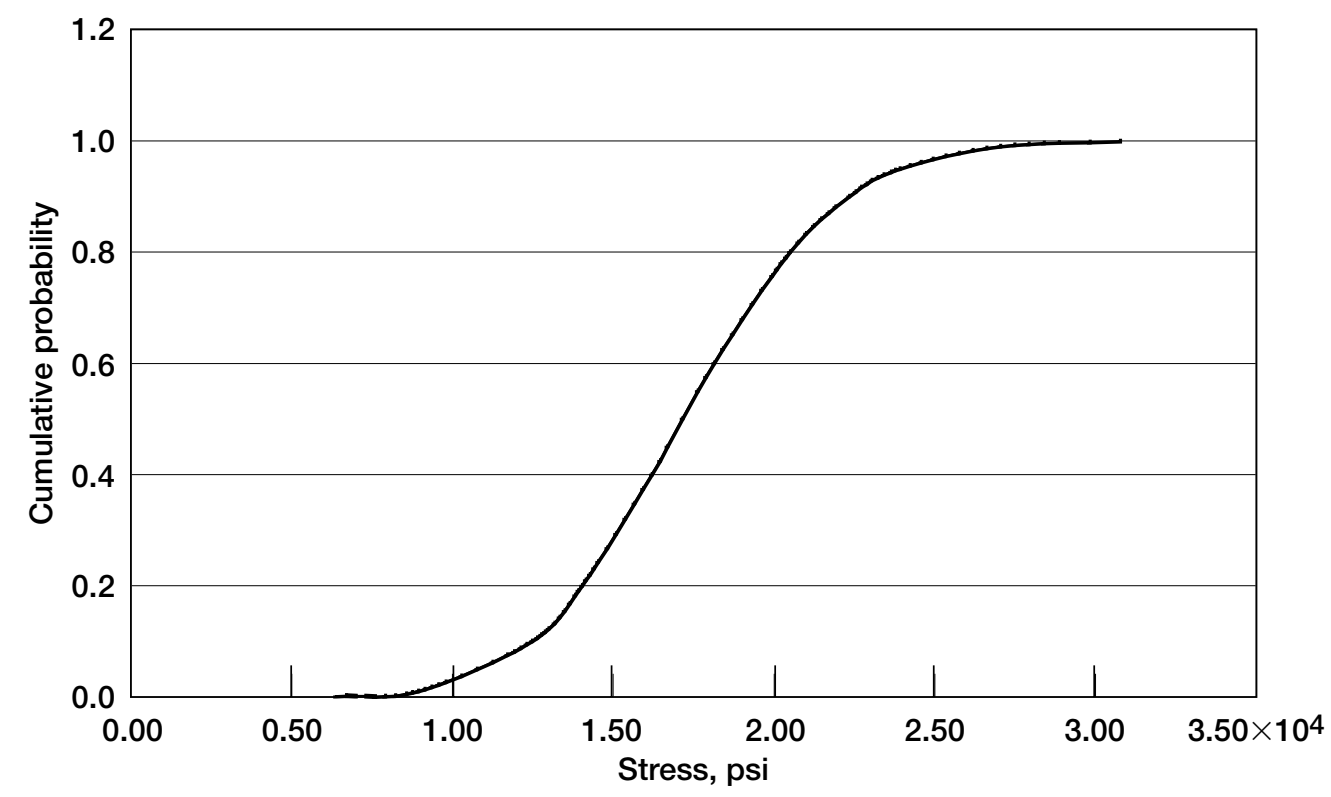

Figure 4.-Cumulative probability of stress.

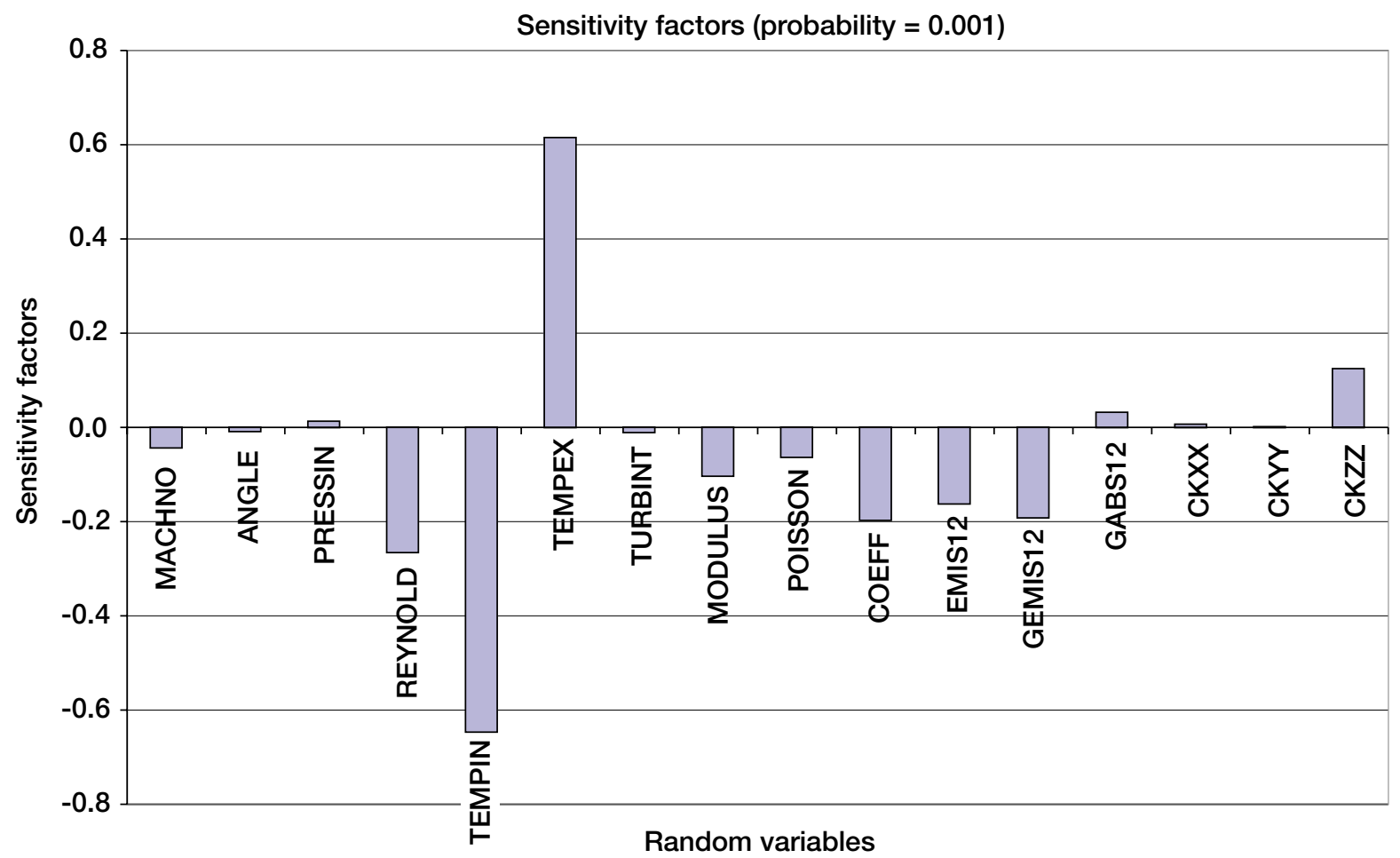

Figure 5.-Sensitivity factors versus random variables. 


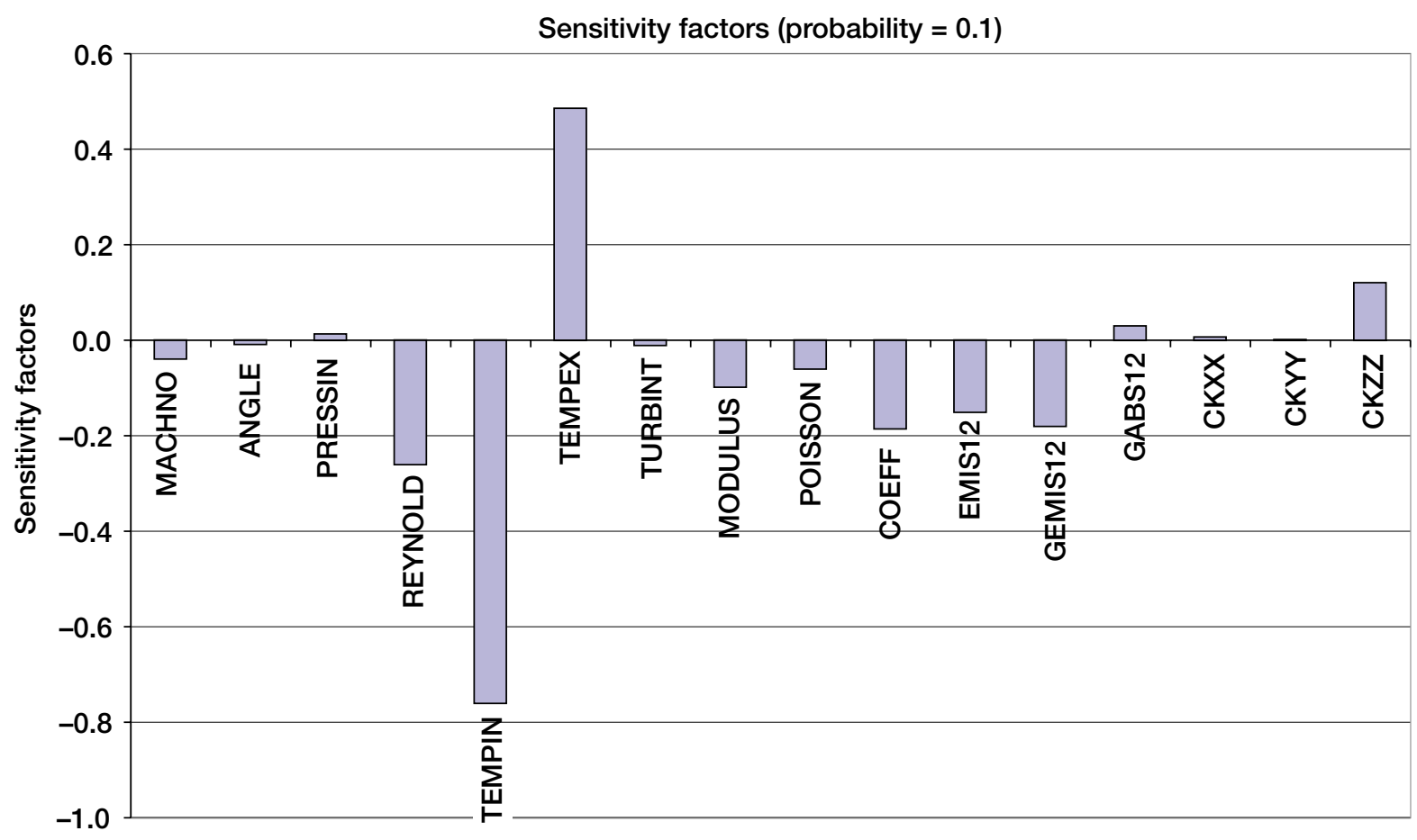

Random variables

Figure 6.-Sensitivity factors versus random variables.

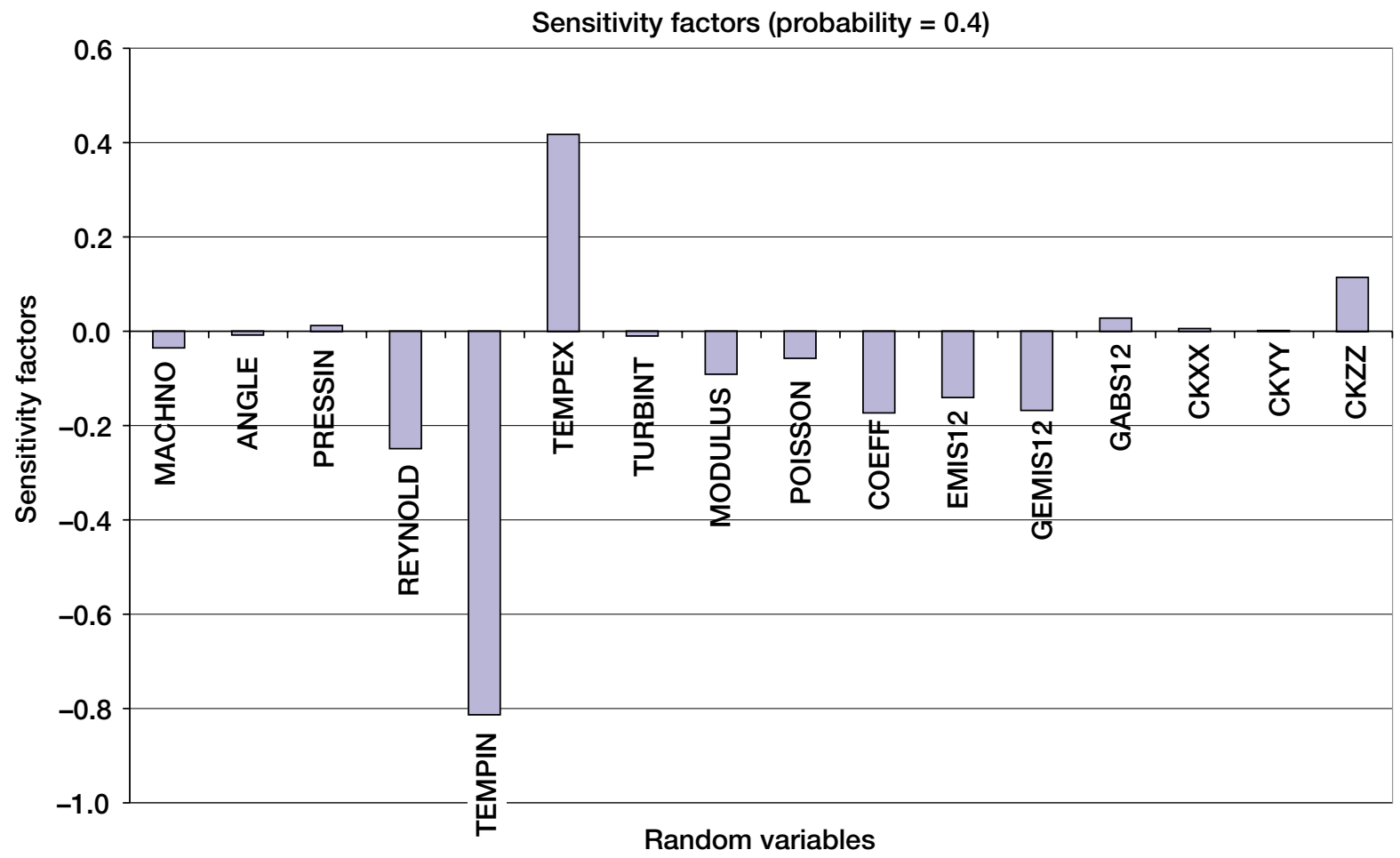

Figure 7.-Sensitivity factors versus random variables. 


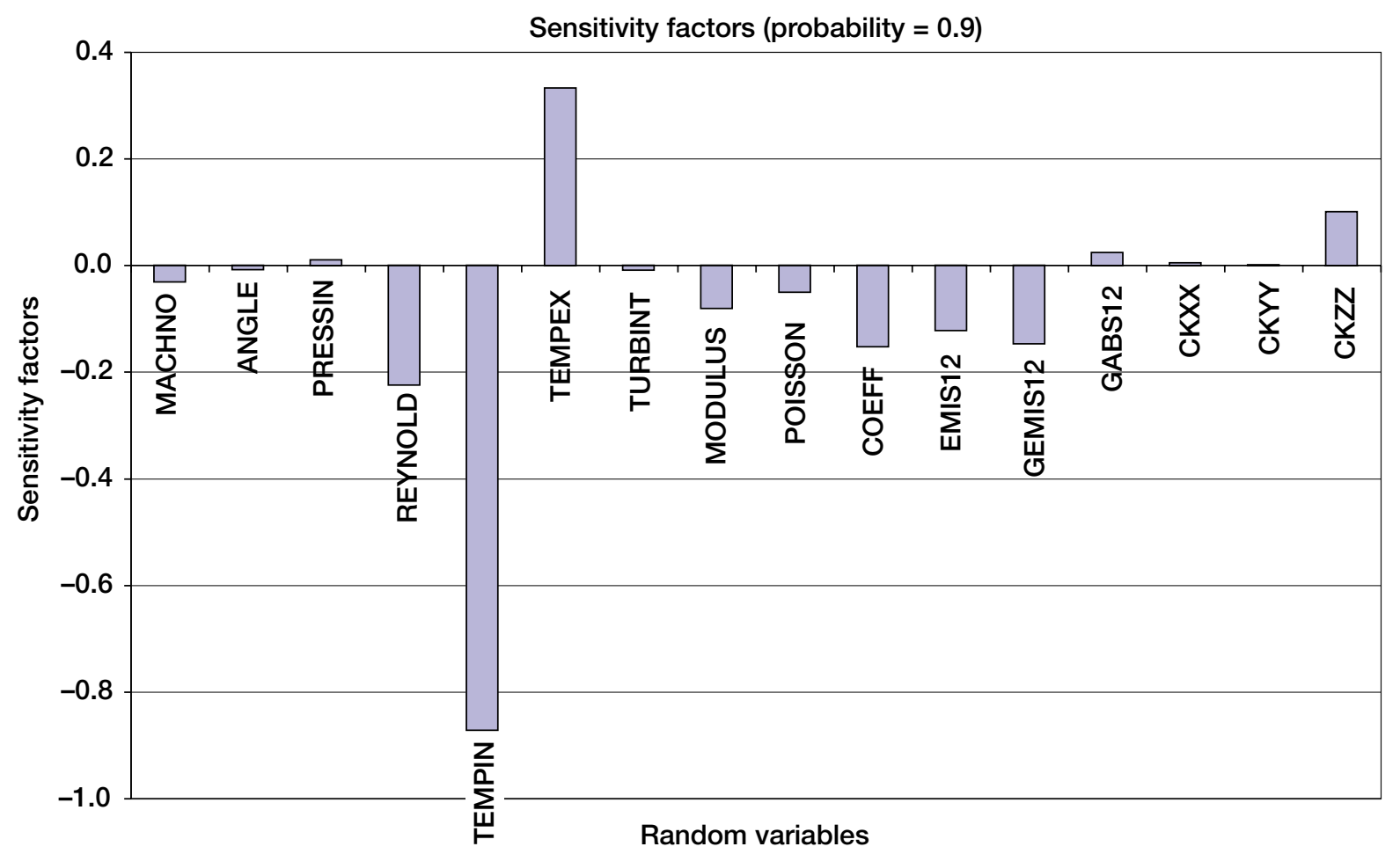

Figure 8.-Sensitivity factors versus random variables.

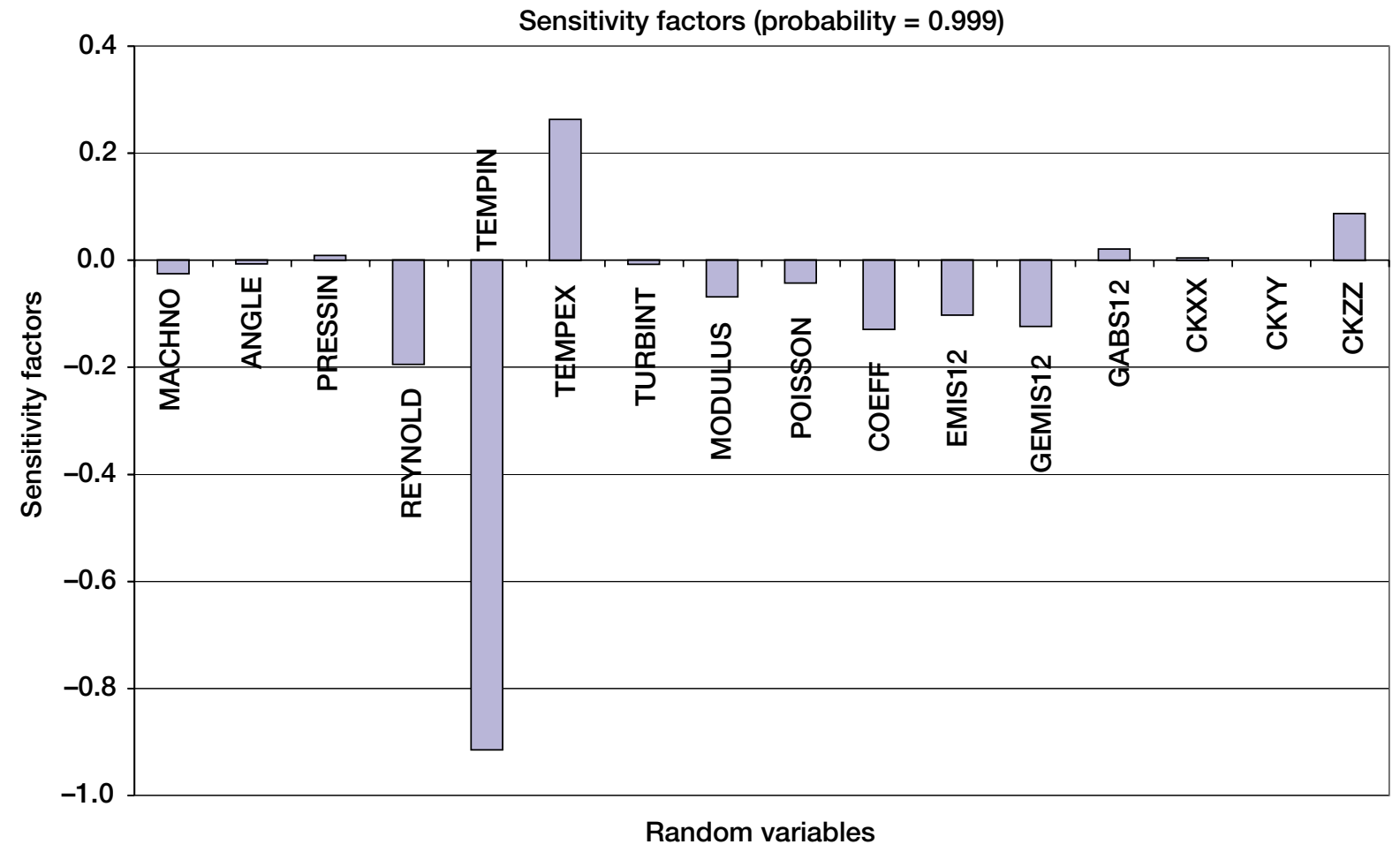

Figure 9.-Sensitivity factors versus random variables. 
Public reporting burden for this collection of information is estimated to average 1 hour per response, including the time for reviewing instructions, searching existing data sources, gathering and maintaining the data needed, and completing and reviewing the collection of information. Send comments regarding this burden estimate or any other aspect of this collection of information, including suggestions for reducing this burden, to Washington Headquarters Services, Directorate for Information Operations and Reports, 1215 Jefferson Davis Highway, Suite 1204, Arlington, VA 22202-4302, and to the Office of Management and Budget, Paperwork Reduction Project (0704-0188), Washington, DC 20503.

\begin{tabular}{|l|l|l}
\hline 1. AGENCY USE ONLY (Leave blank) & $\begin{array}{c}\text { 2. REPORT DATE } \\
\text { March } 2002\end{array}$ & $\begin{array}{r}\text { 3. REPORT TYPE AND DATES COVERED } \\
\text { Technical Memorandum }\end{array}$ \\
\hline
\end{tabular}

4. TITLE AND SUBTITLE 5. FUNDING NUMBERS

Probabilistic Study of Fluid Structure Interaction

6. AUTHOR(S)

WU-323-71-00-00

Rama S.R. Gorla, Shantaram S. Pai, and Jeffrey J. Rusick

7. PERFORMING ORGANIZATION NAME(S) AND ADDRESS(ES)

National Aeronautics and Space Administration

John H. Glenn Research Center at Lewis Field

Cleveland, Ohio 44135-3191

8. PERFORMING ORGANIZATION REPORT NUMBER

E-13197

9. SPONSORING/MONITORING AGENCY NAME(S) AND ADDRESS(ES)

National Aeronautics and Space Administration

Washington, DC 20546-0001

10. SPONSORING/MONITORING

AGENCY REPORT NUMBER

NASA TM-2002-211374

GT-2002-30308

\section{SUPPLEMENTARY NOTES}

Prepared for the Turbo Expo 2002 sponsored by the American Society of Mechanical Engineers and the International Gas Turbine Institute, Amsterdam, The Netherlands, June 3-6, 2002. Rama S.R. Gorla, Cleveland State University, Cleveland, Ohio 44115; Shantaram S. Pai and Jeffrey J. Rusick, NASA Glenn Research Center. Responsible person, Jeffrey J. Rusick, organization code $0510,216-433-5375$.

12a. DISTRIBUTION/AVAILABILITY STATEMENT

12b. DISTRIBUTION CODE

Unclassified - Unlimited

Subject Category: 02

Distribution: Nonstandard

Available electronically at http://gltrs.grc.nasa.gov/GLTRS

This publication is available from the NASA Center for AeroSpace Information, 301-621-0390.

13. ABSTRACT (Maximum 200 words)

A combustor liner was computationally simulated and probabilistically evaluated in view of the several uncertainties in the aerodynamic, structural, material and thermal variables that govern the combustor liner. The interconnection between the computational fluid dynamics code and the finite element structural analysis codes was necessary to couple the thermal profiles with structural design. The stresses and their variations were evaluated at critical points on the liner. Cumulative distribution functions and sensitivity factors were computed for stress responses due to the aerodynamic, mechanical and thermal random variables. It was observed that the inlet and exit temperatures have a lot of influence on the hoop stress. For prescribed values of inlet and exit temperatures, the Reynolds number of the flow, coefficient of thermal expansion, gas emissivity and absorptivity and thermal conductivity of the material have about the same impact on the hoop stress. These results can be used to quickly identify the most critical design variables in order to optimize the design and make it cost effective.

14. SUBJECT TERMS 15. NUMBER OF PAGES

Probabilistic evaluation; Fluid structure interaction; Combustor liner; Structural analysis; Computational fluid dynamics

17. SECURITY CLASSIFICATION OF REPORT

Unclassified

18. SECURITY CLASSIFICATION
OF THIS PAGE
Unclassified

Unclassified
19. SECURITY CLASSIFICATION OF ABSTRACT

Unclassified 